\title{
The effect of different selenium sources during the finishing phase on beef quality
}

\author{
C.A. Sgoifo Rossi ${ }^{1,4}$, R. Compiani', G. Baldi', C.E.M. Bernardi', M. Muraro², \\ J.-P. Marden ${ }^{3}$ and V. Dell'Orto ${ }^{1}$ \\ ${ }^{1}$ University of Milan, Department of Health, Animal Science and Food Safety, Via G. Celoria 10, 20133, Milan, Italy \\ ${ }^{2}$ Consorzio Agrario Lombardo Veneto, Via Francia 2, 37135, Verona, Italy \\ ${ }^{3}$ Lesaffre Feed Additives, 137 rue Gabriel Péri, 59700 Marcq-en-Barœul, France
}

KEY WORDS: beef heifers, beef quality, beef shelf-life, meat colour, selenium, yeast

Received: 11 August 2014

Revised: 3 June 2015

Accepted: 15 June 2015

${ }^{4}$ Corresponding author:

e-mail: carlo.sgoifo@unimi.it

\begin{abstract}
Selenium (Se) is involved in several biological functions and its supplementation is necessary for farm animals. Se can be provided in organic or inorganic forms, which are metabolized differently. The aim of this study was to compare the effects of switching the Se source in the last 60 days of fattening on beef quality and Se content in meat. Charolaise beef heifers supplemented since the beginning of the fattening period with sodium selenite (162 heads; $517 \pm 61$ days of age) were divided into two groups, fed the same diet, in which Se $\left(0.2 \mathrm{mg} \mathrm{Se} \cdot \mathrm{kg}^{-1} \mathrm{DM}\right.$ of feed) was provided as sodium selenite (SS; 82 heads, $450.7 \pm 33.7 \mathrm{~kg}$ body weight $-\mathrm{BW}$ ) or selenium-enriched yeast (Se-Y; 80 heads, $454.6 \pm 41.7 \mathrm{~kg} \mathrm{BW}$ ). The Se source did not affect growth performance, meat centesimal composition, thawing loss, cooking or drip losses, and pH during 8 days of aerobic storage. Se-Y supplementation improved the meat Se content $(P<0.001)$ and tended to reduce shear force $(P=0.076)$ at $48 \mathrm{~h}$ post mortem. Lightness $(P<0.01)$ and yellowness $(P<0.01)$ decreased with the duration of storage and were higher in the Se-Y group compared with the SS group during 8 days of storage. Meat from group Se-Y also showed a better visual score for colour $(P<0.01)$, odour $(P<0.05)$, surface wetness $(P<0.05)$ and overall appearance $(P<0.01)$. Under the given experimental conditions, switching beef heifers from inorganic to organic Se in the last two months of fattening improved meat tenderness, shelf life, colour stability and muscle Se content.
\end{abstract}

\section{Introduction}

Selenium (Se), in form of selenocysteine, is present at the active site of glutathione peroxidase, thioredoxin reductase, iodothyronine deiodinase, seleno-phosphate synthetase 2 , selenoprotein $\mathrm{P}$, and different kinds of selenoproteins, and is, therefore, involved in the reduction of oxidized antioxidants, scavenging reactive oxygen species, synthesis of thyroid hormones, protection of DNA and proteins from oxidation, redox signals, and immune responses (Lu and Holmgren, 2009). Thanks to these biological roles, Se supplementation improves ruminants' immune response, neutrophil and lymphocyte 
activity and disease resistance (Finch and Turner, 1996; Spears, 2000; Chauhan et al., 2014). These results, coupled with the soil deficiency of Se in large areas of the world (Gissel-Nielsen, 1987; Cantor, 1997; McDowell, 1997; Oldfield, 2002), underline the need to administer supplementary Se to farm animals. Dietary Se can be supplemented through inorganic or organic forms. The first are mainly represented by mineral salts such as selenite or selenate of sodium or cobalt, while, the latter, by selenium-enriched yeast (Se-Y), in which the main selenocompund is represented by selenomethionine (SeMet), or SeMet itself (mainly produced from selenium enriched yeasts; Korhola et al., 1986). Due to a different metabolism, inorganic forms are characterized by a lower bioavailability than organic forms (Weiss, 2005). In terms of beef and veal quality and oxidative stability, although organic supplementation generally increased the meat Se content compared with inorganic supplements at the same dosage (Juniper et al., 2008; Cozzi et al., 2011; Richards et al., 2011), inconsistencies in the effects on meat quality have been reported. Despite long-term organic Se supplementation can significantly increases dietary costs, only Cozzi et al. (2011) have studied short-term supplementation in bullocks. Thanks to the higher bioavailability of organic Se, we hypothesize that short-term supplementation may be able to improve meat quality and Se content, with a minimal impact on production cost. In the present study, a short-term supplementation strategy has been tested on beef heifers, chosen because they nowadays already represent a premium product at the retail lev$\mathrm{el}$, and are, therefore, more suitable for high-Se beef production compared with bullocks.

\section{Material and methods}

\section{Animals and animal care}

The study was performed in a commercial intensive beef fattening farm located in the northeast of Italy. A total of 162 Charolaise heifers, of average age of $517 \pm 61$ days, were enrolled and randomly assigned to the two dietary treatments: sodium selenite (SS) or selenium-enriched yeast (Se-Y). Animals were housed in two large open-air yards, one per treatment, with a full concrete floor covered with maize stoves. The trial was conducted during the last 60 days prior to slaughter. The SS group included 82 heads with an average body weight (BW) of $450.7 \pm 33.7 \mathrm{~kg}$, while the Se-Y group included 80 heads with average BW of $454.6 \pm 41.7 \mathrm{~kg}$. Animal care and treatment were in accordance with the European Community 1986 guidelines No. 609.

\section{Experimental diets and feeding routine}

The heifers were fed the same basal diet (\%: maize silage 43.3, ryegrass silage 14.4 , high moisture maize 19.3, wheat bran 7.2, maize gluten feed dry 4.8, and protein-fibrous mix 11.0) containing as fed, \%: crude protein 26.2 , ether extract 4.5 , crude fibre 10.5 , ash 13.8, UI $\cdot \mathrm{kg}^{-1}$ : vitamin A $40000, \mathrm{mg} \cdot \mathrm{kg}^{-1}$ : vitamin $\mathrm{D}_{3} 4000$, vitamin E 120.0, vitamin $\mathrm{B}_{1} 2.4$, vitamin H 1.6, niacin 400.0, Co 0.8, Mn 120.0, Se 3.2, Zn 200.0, Fe 85.5, I 4.0, urea 24.5, formulated to meet or exceed NRC nutritional requirements (NRC, 2000), differing only in selenium source: SS or Se-Y (SelsafEC No. 3b8.12), produced by Saccharomyces cerevisiae (strain CNCM-I3399, Lesaffre Feed Additives Italia, Italy), in which inorganic Se accounted for less than $1 \%$ of the total Se. Organic selenocompounds were mainly represented by selenomethionine $(62.7 \%)$ and selenocysteine $(2 \%$ to $4 \%$ of total $\mathrm{Se}$ ), while the remaining organic $\mathrm{Se}$ compounds were not specified (EFSA, 2009). Se was supplemented through the mineral and vitamin mix, and its inclusion was targeted to provide $0.2 \mathrm{mg} \mathrm{Se} \cdot \mathrm{kg}^{-1} \mathrm{DM}$ of feed. Experimental diets were administered ad libitum and delivered in total mixture ratio (TMR) form once a day in the morning by a feed mixer wagon, provided with a balance to weigh the inclusion of each ingredient. Water was available ad libitum.

\section{Growth performance and health status}

Individual weight was recorded prior to the morning feeding on enrolment (day 0) and the day before slaughter (day 60) and average daily gain (ADG) was subsequently calculated.

Health status was monitored daily by the veterinarian staff and no adverse clinical symptom was recorded.

\section{Meat samples and analysis}

At the end of the finishing period, the animals were slaughtered at the same slaughterhouse and carcass characteristics were recorded. After slaughtering, conformation (SEUROP) and fattening score (1-5) were assessed by an expert judge following EU legislation (Council Regulation (EEC) No. 1026/91). Cold carcass weight was obtained after $48 \mathrm{~h}$ of chilling at a temperature of $0^{\circ} \mathrm{C}$ to $4^{\circ} \mathrm{C}$ and, at the same time, samples of the longissimus thoracis muscle between the $5^{\text {th }}$ and the $7^{\text {th }}$ rib were taken from 30 homogenous carcasses for the experimental group.

Each sample was divided into three subsamples, two $2.50 \mathrm{~cm}$ steaks, used fresh, the first one to evaluate meat colour, $\mathrm{pH}$, water holding 
capacity (WHC), and the second for shelf-life assessment, daily for 8 consecutive days. The third subsample was weighed, vacuum-packaged, and kept frozen at $-20^{\circ} \mathrm{C}$ until chemical and physical analysis. The shelf-life of each steak, kept in a plastic box, overwrapped with polyethylene film and kept at $0^{\circ} \mathrm{C}$ to $4^{\circ} \mathrm{C}$ in a dark room, was visually assessed daily by a three-member expert food inspector panel, which evaluated lean colour ( 8 - bright cherry-red, 1 - extremely dark brown or green/grey), overall appearance $(8$ - extremely desirable, 1 - extremely undesirable), surface wetness ( 7 - humid and bright; 4 - dry), and odour ( 7 - 'fresh beef' odour; 5 - no odour; 3 - slight odour development but still acceptable; 2 - definite off-odour indicative of spoiled beef; 1 - very strong off-odour associated with spoiled beef); the average of the three observations was considered for statistical analysis. On the other sample, kept under the same conditions, $\mathrm{pH}$ and instrumental colour were recorded daily, while drip-loss was assessed at the beginning and at the end of storage. Measurements of $\mathrm{pH}$ were made by a portable pH-meter (HI 98150, HANNA Instruments Inc., Woonsocket, RI, USA) equipped with a glass electrode ( $3 \mathrm{~mm} \varnothing$ conic tip) suitable for meat penetration; values for each sample came from the average of three measurements. Colour determination was performed using a CR310 Chromameter, set on D65 illuminance, view angle $10^{\circ}$, calibrated on the CIELab colour space system using a white calibration plate (Calibration Plate CR-A43, Minolta Cameras) and lightness $\left(L^{*}\right)$, redness $\left(a^{*}\right)$, and yellowness $\left(b^{*}\right)$, were calculated according to the CIELab system. The colorimeter had an $8-\mathrm{mm}$ measuring area and the average of 10 repetitions was recorded as the value for each sample. For drip loss determination, samples were dried from superficial wetness and weighed at the start and at the end of storage time. Chemical composition (dry matter, ether extract, crude protein and ash) was determined on samples trimmed from external fat and connective tissue and homogenized for $30 \mathrm{sec}$ according to AOAC (1990). Thawing loss was assessed by weighing, freezing, and weighing after $24 \mathrm{~h}$ of thawing at $4{ }^{\circ} \mathrm{C}$. Cooking loss was determined, as described by Honikel (1998), as the weight lost after cooking in a water bath until the core temperature reached $75^{\circ} \mathrm{C}$ (monitored with a temperature meter HI98840, HANNA Instruments Inc., Woonsocket, RI, USA) and $24 \mathrm{~h}$ of storage at $4^{\circ} \mathrm{C}$. Before being weighed, the samples were blotted dry. The difference between pre- and post-cooking weights was used to calculate the percentage loss during cooking. After cooking loss determination, six cylindrical cores, $1.27 \mathrm{~cm}$ in diameter, parallel to fibre orientation, were obtained and used for shear force evaluation, using a Warner-Bratzler shear force texture analyser (model 4466; Instron Corp., Canton, MA, USA). The peak force $\left(\mathrm{kg} \cdot \mathrm{cm}^{2}\right)$ was then recorded.

\section{Meat selenium content}

The selenium content in fresh meat was assessed by a commercial laboratory using ICP-MS methods (Agilent $7500 \mathrm{cx}$ ICP-MS, Agilent Techmologies, Santa Clara, CA, USA). Analytical procedures were performed following UNI CEI EN ISO/IEC 17025:2005 standards.

\section{Statistical analysis}

Body weight, average daily gain, meat selenium content, shear force and drip loss were analysed by one-way ANOVA (SAS, 2011) considering the main effect of treatment. Colour parameters, $\mathrm{pH}$ and visual evaluation score were analysed by a two-way ANOVA using a general linear model for repeated measures, considering the effects of treatment, storage time and their interaction (SAS, 2011). The significance level was set and discussed for $P \leq 0.05$, while $P \leq 0.10$ was considered a tendency.

\section{Results}

Final body weight, average daily gain and carcass characteristics did not differ between groups (Table 1).

Meat centesimal composition in the selected carcasses was not affected by treatment, while Se-Y supplementation markedly increased the meat selenium content $(P<0.001$; Table 2$)$. The replacement of SS with Se-Y tended to reduce shear force on cooked samples $(P=0.076$; Figure 1$)$. The Se source did not affect thawing, cooking, or drip losses after 8 days of storage (Table 2). During storage, the $\mathrm{pH}$ increased $(P<0.001)$, but was not affected by treatment (Table 3). Regarding colour parameters, lightness $\left(L^{*}\right)$ was affected by treatment $(P<0.01)$, storage time $(P<0.01)$, and their interaction $(P<0.05)$,

Table 1. Least square means for the effect of selenium source during finishing phase on rearing performance

\begin{tabular}{lcccc}
\hline Indices & \multicolumn{2}{l}{ Groups } & \multirow{2}{*}{ SEM } & \multirow{2}{*}{$P$} \\
\cline { 2 - 3 } & SS & Se-Y & & \\
\hline Average initial BW, $\mathrm{kg}$ & 450.4 & 454.6 & 4.28 & 0.48 \\
Average final BW, kg & 529.5 & 535.3 & 4.94 & 0.40 \\
ADG, $\mathrm{kg} \cdot \mathrm{d}^{-1}$ & 1.39 & 1.42 & 0.03 & 0.53 \\
\hline
\end{tabular}

SS - sodium selenite; Se-Y - selenium-enriched yeast; BW - body weight; $A D G$ - average daily gain 
Table 2. Least square means for the effect of selenium source during finishing phase on meat chemical composition, selenium content thawing, drip and cooking loss of the 30 carcass/group

\begin{tabular}{|c|c|c|c|c|}
\hline \multirow{2}{*}{ Indices } & \multicolumn{2}{|l|}{ Groups ${ }^{1}$} & \multirow{2}{*}{ SEM } & \multirow{2}{*}{$P$} \\
\hline & SS & Se-Y & & \\
\hline Cold carcass weight, kg & 318.1 & 319.3 & 2.85 & 0.77 \\
\hline Dressing percentage, $\%$ & 55.08 & 54.95 & 8.03 & 0.42 \\
\hline Humidity, \% & 72.87 & 72.70 & 5.23 & 0.24 \\
\hline Crude protein, $\%$ & 22.73 & 22.96 & 0.09 & 0.10 \\
\hline Ether extract, \% & 3.39 & 3.33 & 0.06 & 0.44 \\
\hline Ash, \% & 1.01 & 1.01 & 0.11 & 0.80 \\
\hline Se, $\mathrm{mg} \cdot \mathrm{kg}^{-1}$ dry matter & 0.425 & 0.791 & 0.07 & $<0.001$ \\
\hline Thawing loss, $\%$ & 0.70 & 0.76 & 0.033 & 0.22 \\
\hline $\begin{array}{l}\text { Drip loss, } \% \text { after } \\
8 \text { days of storage }\end{array}$ & 2.06 & 2.05 & 0.09 & 0.98 \\
\hline Cooking loss, $\%$ & 29.31 & 29.17 & 0.76 & 0.79 \\
\hline
\end{tabular}

${ }^{1}$ see Table 1

Table 3. Least square means for the effect of selenium source during finishing phase on meat $\mathrm{pH}$ during 8 days of storage

\begin{tabular}{|c|c|c|c|}
\hline \multirow{2}{*}{$\begin{array}{l}\text { Days } \\
\text { of storage }\end{array}$} & \multicolumn{2}{|c|}{ Meat pH } & \multirow{2}{*}{ SEM } \\
\hline & $\mathrm{SS}^{1}$ & $\mathrm{Se}-\mathrm{Y}^{2}$ & \\
\hline 1 & 5.70 & 5.69 & 0.023 \\
\hline 2 & 5.70 & 5.77 & 0.033 \\
\hline 3 & 5.73 & 5.77 & 0.015 \\
\hline 4 & 5.79 & 5.77 & 0.023 \\
\hline 5 & 5.73 & 5.74 & 0.028 \\
\hline 6 & 5.75 & 5.76 & 0.021 \\
\hline 7 & 5.91 & 5.88 & 0.032 \\
\hline 8 & 5.92 & 5.99 & 0.040 \\
\hline$P(s)^{3}$ & \multicolumn{3}{|c|}{0.60} \\
\hline$P(t)^{3}$ & \multicolumn{3}{|c|}{$<0.001$} \\
\hline$P(s \times t)^{3}$ & \multicolumn{3}{|c|}{0.06} \\
\hline
\end{tabular}

${ }^{1,2}$ see Table $1 ;{ }^{3} \mathrm{~s}$ - selenium source; $\mathrm{t}$ - storage time; $\mathrm{s} \times \mathrm{t}$ - selenium source $\times$ storage time

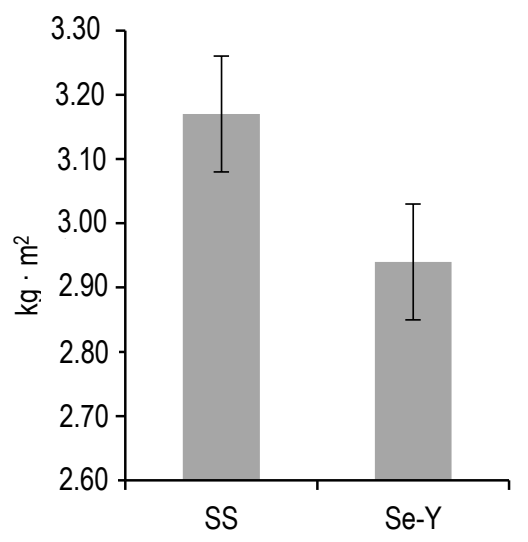

Figure 1. Least square means ( \pm SEM) for the effect of selenium source during finishing phase on shear force at $48 \mathrm{~h}$ post mortem $(P=0.076)$; SS - sodium selenite; Se-Y - selenium-enriched yeast and the treated group was characterized by significantly higher $L^{*}$ values. In the same way, redness $\left(a^{*}\right)$ decreased with increasing storage time $(P<0.01)$, but was not affected by selenium source or their interaction. The treated group also showed a higher yellowness $\left(b^{*}\right)(P<0.01)$, which decreased in both groups during storage $(P<0.01)$, but was not affected by the interaction between treatment and storage time (Figure 2). Considering also the decreasing trend of lightness and redness, samples from animals fed Se-Y showed higher $L^{*}$ and $a^{*}$ stability during the first days of storage (Figure 2). Meat shelf-life was also affected by treatment and storage time (Table 4). As expected, colour, odour, surface wetness, and overall appearance scores decreased during storage $(P<0.001)$ and the selenium source positively affected all of these
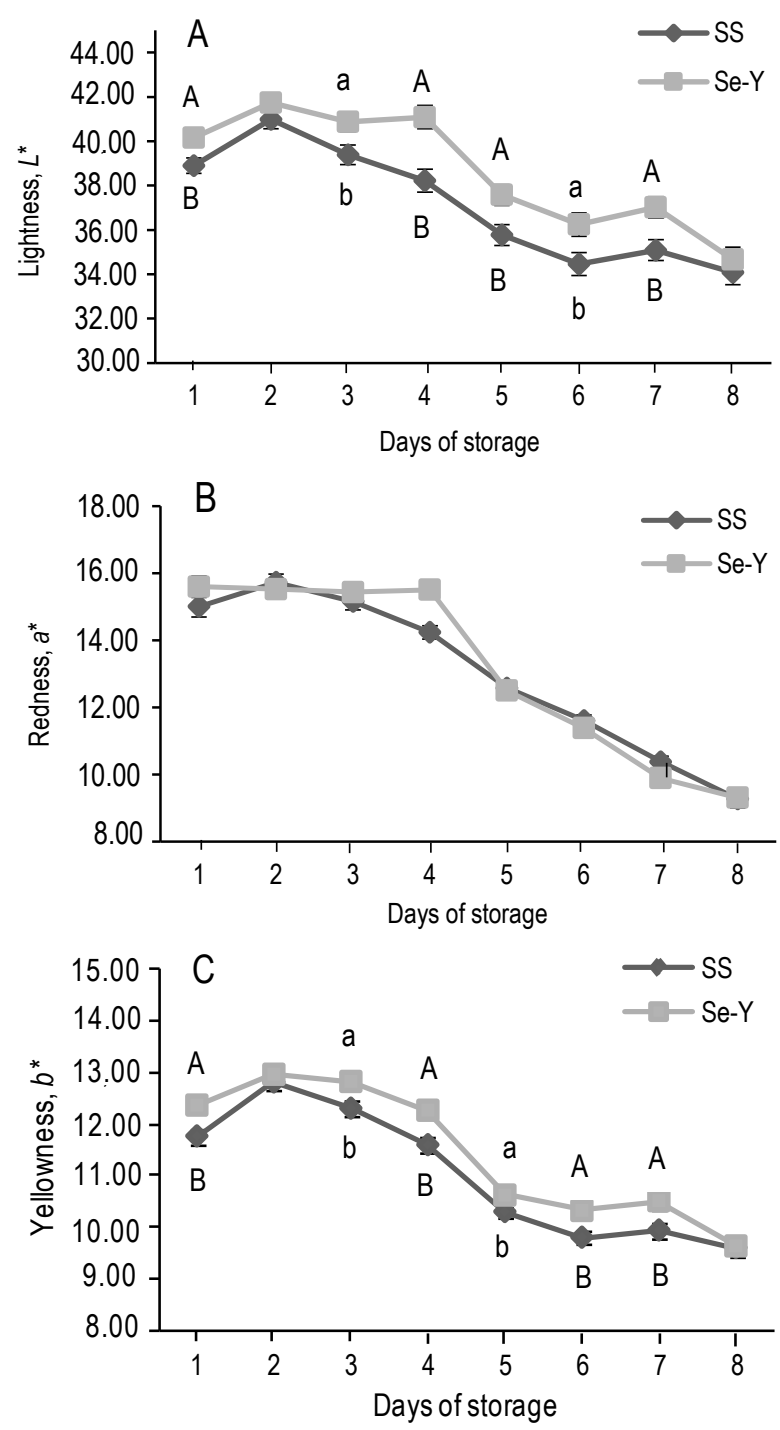

Figure 2. Least square means ( \pm SEM) for the effect of selenium source during finishing phase on lightness $(A)$, redness $(B)$ and yellowness $(C)$ during 8 days of storage $\left({ }^{A, B} P \leq 0.01\right.$; $\left.{ }^{a, b} P \leq 0.05\right)$; $S S$, Se-Y - see Figure 1 
Table 4. Least square means for the effect of selenium source during finishing phase on colour, odour, surface wetness and overall appearance score during 8 days of storage

\begin{tabular}{|c|c|c|c|c|c|c|c|c|c|c|c|c|}
\hline \multirow{2}{*}{$\begin{array}{l}\text { Days } \\
\text { of storage }\end{array}$} & \multicolumn{3}{|c|}{ Colour } & \multicolumn{3}{|c|}{ Odour } & \multicolumn{3}{|c|}{ Surface wetness } & \multicolumn{3}{|c|}{ Overall appearance } \\
\hline & $\mathrm{SS}^{1}$ & Se-Y ${ }^{2}$ & SEM & SS & Se-Y & SEM & SS & Se-Y & SEM & SS & Se-Y & SEM \\
\hline 1 & 7.43 & 7.71 & 0.193 & 7.02 & 7.11 & 0.201 & 6.71 & 6.83 & 0.184 & 7.61 & 7.80 & 0.184 \\
\hline 2 & 6.86 & 7.29 & 0.226 & 6.42 & 6.71 & 0.330 & 5.81 & 6.14 & 0.274 & 6.85 & 7.14 & 0.261 \\
\hline 3 & 6.09 & 6.57 & 0.303 & 5.57 & 6.14 & 0.387 & 5.28 & 5.69 & 0.286 & 5.58 & 6.28 & 0.247 \\
\hline 4 & $5.03^{a}$ & $5.86^{\mathrm{b}}$ & 0.240 & 4.14 & 4.71 & 0.350 & 4.29 & 4.57 & 0.193 & $4.46^{\mathrm{a}}$ & $5.15^{b}$ & 0.241 \\
\hline 5 & $4.43^{\mathrm{a}}$ & $5.11^{b}$ & 0.210 & 2.71 & 2.86 & 0.165 & $4.02^{\mathrm{a}}$ & $4.31^{b}$ & 0.143 & $3.71^{\mathrm{a}}$ & $4.28^{b}$ & 0.286 \\
\hline 6 & $3.57^{\mathrm{A}}$ & $4.43^{B}$ & 0.202 & 1.43 & 1.71 & 0.193 & $3.15^{\mathrm{a}}$ & $3.65^{b}$ & 0.136 & $2.42^{\mathrm{a}}$ & $3.21^{\mathrm{b}}$ & 0.193 \\
\hline 7 & $2.75^{\mathrm{A}}$ & $3.95^{\mathrm{B}}$ & 0.233 & $1.00^{\mathrm{a}}$ & $1.45^{b}$ & 0.143 & $2.12^{\mathrm{A}}$ & $2.97^{B}$ & 0.150 & $1.57^{\mathrm{A}}$ & $2.42^{B}$ & 0.202 \\
\hline 8 & $2.14^{\mathrm{A}}$ & $3.29^{B}$ & 0.274 & $1.00^{\mathrm{a}}$ & $1.29^{b}$ & 0.130 & $1.56^{\mathrm{A}}$ & $1.98^{B}$ & 0.183 & $1.14^{\mathrm{A}}$ & $1.86^{\mathrm{B}}$ & 0.143 \\
\hline$P(\mathrm{~s})^{3}$ & \multicolumn{3}{|c|}{$<0.01$} & \multicolumn{3}{|c|}{$<0.05$} & \multicolumn{3}{|c|}{$<0.05$} & \multicolumn{3}{|c|}{$<0.01$} \\
\hline$P(t)^{3}$ & \multicolumn{3}{|c|}{$<0.001$} & \multicolumn{3}{|c|}{$<0.001$} & \multicolumn{3}{|c|}{$<0.001$} & \multicolumn{3}{|c|}{$<0.001$} \\
\hline$P(s \times t)^{3}$ & \multicolumn{3}{|c|}{0.68} & \multicolumn{3}{|c|}{0.84} & \multicolumn{3}{|c|}{0.76} & \multicolumn{3}{|c|}{0.49} \\
\hline
\end{tabular}

1,2 see Table $1 ;{ }^{3}$ see Table 3 ; ${ }^{A B}$, ab means with different superscipts within a row are significantly different at $P \leq 0.01$ or $P \leq 0.05$, respectively

visual parameters. The colour score was higher in the Se-Y group $(P<0.01)$ from the fourth day, the odour score was higher $(P<0.05)$ on the last two days, while surface wetness was higher $(P<0.05)$ starting from the fifth day of storage. The overall appearance benefited from these ameliorating effects and its score was increased by administration of organic selenium $(P<0.01)$ starting from the fourth day of storage.

\section{Discussion}

The absence of the effect of Se source on growth performance and carcass traits is consistent with other studies in fattening cattle (Nicholson et al., 1991; Cozzi et al., 2011), male goats (Shi et al., 2011) and lambs (Vignola et al., 2009). Similarly, absence of an effect of Se source on meat centesimal composition was also reported by Taylor et al. (2008) and Cozzi et al. (2011) in beef, and by Vignola et al. (2009) in lambs. Given that Se is mainly implicated in improving immune response, as previously reported, this result was expected, as the final stage of the fattening cycle is not a critical stage for infectious diseases. Indeed the disease most impacting beef cattle production is bovine respiratory disease (Radostits et al., 2007), which affects, especially, newly received beef cattle (Galyean et al., 1999). The rise in the muscular Se concentration achieved by supplementing $\mathrm{Se}-\mathrm{Y}$ in respect to $\mathrm{SS}$ is consistent with the findings of Juniper et al. (2008) and Cozzi et al. (2011) in beef, Juniper et al. (2009) and Vignola et al. (2009) in lambs, and Shi et al. (2011) in growing male goats. This confirms the greater bioavailability of the organic compared with the inorganic form. Indeed, at the rumen level, part of the dietary SeMet, the prevalent form in the provided Se-Y, is incorporated into bacterial protein, thus becoming part of metabolizable protein. The remaining amount is efficiently absorbed at the gut level through methionine carriers. In contrast, most of the selenate is reduced to selenite and subsequently converted into weakly absorbable compounds or used by microbes to synthesize seleno-amino acids. The escaped selenate is actively absorbed via a cotransport pathway along with sodium ions, while selenite is absorbed via passive transfer. After absorption, SeMet can be incorporated into proteins, in replacement of met-hionine, or catabolized and the Se utilized for $\mathrm{SeCys}$ synthesis. The absorbed selenite is reduced instead to selenide, utilized to synthesize SeCys, while the portion not immediately converted to SeCys is methylated and excreted (Weiss, 2005). Increasing the meat Se content is an important outcome, as meat is one of the major contributors to Se intake in the human diet and a low Se status is linked to a higher risk of mortality, poor immune function, and cognitive decline (Rayman, 2012). Moreover, in the majority of EU countries, Se intake is lower than the recommended value of $55 \mu \mathrm{g} \cdot$ day $^{-1}$ (Rayman, 2004; Thomson, 2004). Overall, from an economic perspective, given the short-term supplementation and, especially, the small amount provided, it is possible to conclude that the replacement of inorganic Se with Se-enriched yeast does not significantly affect beef production costs. Moreover, the higher bioavailability can allow producing selenium-enriched meat with a consequently higher added value. An increase in beef tenderness has also been reported by Cozzi et al. (2011). In our trial we found a reduction of shear force at $48 \mathrm{~h}$ post mortem and, considering the positive relationship found between meat selenium content and glutathione peroxidase (GSH-Px) activity (Juniper et al., 2008), 
this may be explained by lower calpain oxidation due to the highest GSH-Px activity in the Se-Y group. Indeed, during post mortem muscular proteins undergo to a marked oxidation that could impair meat tenderness by decreasing protease activity and inducing myofibrillar protein cross-linking (Huff Lonergan et al., 2010; Estevez, 2011; Lund et al., 2011). As reviewed by the same authors, both $\mu$ - and m-calpains contain histidine and cysteine thiol groups in their active site; these groups are highly susceptible to oxidation resulting in inactivation. Moreover, cross-linking of myofibrillar proteins reduces their susceptibility to degradation and improves the strength of the myofibrillar structure, increasing meat toughness. In this scenario, is possible to hypothesize that the increase of muscular antioxidant activity due to the higher Se content could have reduced the extent of enzymatic and myofibrillar protein oxidation. This hypothesis is supported by the findings of Rowe et al. (2004a,b), who reported that dietary antioxidant supplementation in beef (vitamin E) reduced protein oxidation, positively promoting post mortem proteolysis and, consequently, beef tenderness. Nevertheless, further investigations are necessary to better clarify the role of Se in the meat tenderization process, protease activity, and protein oxidation.

The lack of effect of selenium source on meat drip loss is consistent with the findings of Cozzi et al. (2011) in beef and Vignola et al. (2009) in lambs. In contrast, some authors reported an increase in WHC in subjects supplemented with an organic selenium source in respect to those fed an inorganic one in studies on poultry (Downs et al., 2000; Wang et al., 2011a,b) and pigs (Mateo et al., 2007; Zhan et al., 2007).

Regarding meat $\mathrm{pH}$, our findings are in agreement with those of Zhan et al. (2007) in pigs, Vignola et al. (2009) in lambs, and Juniper et al. (2011) in turkeys. Cozzi et al. (2011), in contrast, reported a higher beef $\mathrm{pH}$ after 6 days of ageing in animals fed organic selenium compared with those fed sodium selenite or switched from it to selenium yeast in the last 70 days, but no differences were found by the same authors at 11 days post mortem or between animals fed for the entire fattening period with sodium selenite or switched to selenium yeast, as we did in this trial, at both ageing times. Furthermore, Wang et al. (2011b) found that the $\mathrm{pH}$ tend to be higher in the breast of broilers fed with selenomethionine in comparison with those receiving sodium selenite.

Improvement of lightness due to supplementation of organic selenium was also reported by Cozzi et al., (2011), who found an increased $L^{*}$ value after 6 and 11 days of vacuum packaged ageing. In contrast, Vignola et al. (2009) reported no effects of selenium source on lamb meat lightness, redness and yellowness during 9 days of simulated display life. The same authors did not report differences in meat redness or yellowness. Regarding these two parameters, however, Taylor et al. (2008) found that meat from cattle fed a selenium-enriched diet had a higher Se content and tended to have a higher average $a^{*}$ and $b^{*}$ during 12 days of display, compared with animals fed an unenriched diet. Given that lightness is related to meat protein structure (MacDougall, 1982) and not with myoglobin status (McKenna et al., 2005), therefore, this excluded reduction of myoglobin oxidation as an explanation; the effect of organic selenium on this parameter still remains to be clarified, considering also the above reported inconsistency between studies.

\section{Conclusions}

Under the presented experimental conditions, switching selenium supplementation from sodium selenite to selenium-enriched yeast during the last two months of fattening did not affect heifer performance or meat water holding capacity, but improved meat tenderness and colour stability during storage, with a positive impact on meat shelf life. The present study also confirmed that short-term supplementation represents a valid strategy for increasing meat Se content, an important outcome from the market and human health perspectives. Further investigations are necessary to better clarify the magnitude of and mechanisms involved in the effects of organic Se supplementation on meat colour, as well as the potential impact on the post mortem tenderization process and protein oxidation.

\section{References}

AOAC, 1990. Association of Officinal Analytical Chemists, Official Methods of Analysis. $15^{\text {th }}$ Edition. Arlington, VA

Cantor A.H., 1997. The role of selenium in poultry nutrition. In: T.P. Lyons, K.A. Jacques (Editors). Biotechnology in the Feed Industry: Proceedings of Alltech's $13^{\text {th }}$ Annual Symposium. Nottingham University Press, Nottingham (UK)

Chauhan S.S., Celi P., Ponnampalam E.P., Leruy B.J., Liu F., Dunshea F.R., 2014. Antioxidant dynamics in the live animal and implications for ruminant health and product (meat/milk) quality: role of vitamin E and selenium. Anim. Prod. Sci. 54, 1525-1536

Council Directive of 24 November 1986 on the approximation of laws, regulations and administrative provisions of the Member States regarding the protection of animals used for experimental and other scientific purposes (86/609/EEC)

Council Regulation (EEC) No 1026/91 of 22 April 1991 amending Regulation (EEC) No 1208/81 determining the Community scale for the classification of carcases of adult bovine animals. Official J. L 106 (26/04/1991), 2-3 
Cozzi G., Prevedello P., Stefani A.L., Piron A., Contiero B., Lante A., Gottardo F., Chevaux E., 2011. Effect of dietary supplementation with different sources of selenium on growth response, selenium blood levels and meat quality of intensively finished Charolais young bulls. Animal 5, 1531-1538

Downs K.M., Hess J.B., Bilgili S.F., 2000. Selenium source effect on broiler carcass characteristics, meat quality and drip loss. J. Appl. Anim. Res. 18, 61-72

EFSA, 2009. Scientific Opinion of the Panel on Additives and Products or Substances used in Animal Feed (FEEDAP) on a request from the European Commission on the safety and efficacy of SELSAF (Selenium enriched yeast from Saccharomyces cerevisiae CNCM I-3399) as feed additive for all species. EFSA J. 992, 1-24

Estevez M., 2011. Protein carbonyls in meat systems: A review. Meat Sci. $89,259-279$

Finch J.R., Turner R.J., 1996. Effects of selenium and vitamin E on the immune responses of domestic animals. Res. Vet. Sci. $60,97-106$

Galyean M.L., Perino J.L., Duff G.C., 1999. Interaction of cattle health/ immunity and nutrition. J. Anim. Sci. 77, 1120-1134

Gissel-Nielsen G., 1987. Selenium in the soil-plant system. In: G.F. Combs, J.E. Spallholz, O.A. Levander, J. E. Oldfield (Editors). Selenium in Biology and Medicine. AVI Book, New York, NY, pp. $775-782$

Honikel K.O., 1998. Reference methods for the assessment of physical characteristics of meat. Meat Sci. 49, 447-457

Huff Lonergan E., Zhang W., Lonergan S.M., 2010. Biochemistry of postmortem muscle - Lessons on mechanisms of meat tenderization. Meat Sci. 86, 184-195

Juniper D.T., Phipps R.H., Bertin G., 2011. Effect of dietary supplementation with selenium-enriched yeast or sodium selenite on selenium tissue distribution and meat quality in commercial-line turkeys. Animal 5, 1751-1760

Juniper D.T., Phipps R.H., Ramos-Morales E., Bertin G., 2008. Effect of dietary supplementation with selenium-enriched yeast or sodium selenite on selenium tissue distribution and meat quality in beef cattle. J. Anim. Sci. 86, 3100-3109

Juniper D.T., Phipps R.H., Ramos-Morales E., Bertin G., 2009. Effects of dietary supplementation with selenium enriched yeast or sodium selenite on selenium tissue distribution and meat quality in lambs. Anim. Feed Sci. Tech. 149, 228-239

Korhola M., Vainio A., Edelmann K., 1986. Selenium yeast. Ann. Clin. Res. 18, 65-68

Lu J., Holmgren A., 2009. Selenoproteins. J. Biol. Chem. 284, 723-727

Lund M.N., Heinonen M., Baron C.P., Estevez M., 2011. Protein oxidation in muscle foods: A review. Mol. Nutr. Food Res. 55, 83-95

MacDougall D.B., 1982. Changes in the color and opacity of meat. Food Chem. 9, 75-88

Mateo R.D., Spallholz J.E., Elder R., Yoon I., Kim S.W., 2007. Efficacy of dietary selenium sources on growth and carcass characteristics of growing-finishing pigs fed diets containing high endogenous selenium. J. Anim. Sci. 85, 1177-1183

McDowell L.R., 1997. Minerals for Grazing Ruminants in Tropical Regions. University of Florida (Editor). Gainesville, FL (USA)

McKenna D.R., Mies P.D., Baird B.E., Pfeiffer K.D., Ellebracht J.W., Savell J.W., 2005. Biochemical and physical factors affecting discoloration characteristics of 19 bovine muscles. Meat Sci. $70,665-682$

Nicholson J.W.G., McQueen R.E., Bush R.S., 1991. Response of growing cattle to supplementation with organically bound or inorganic sources of selenium or yeast cultures. Can. J. Anim. Sci. 71, 803-811
NRC, 2000. Nutrient Requirements of Beef Cattle. $7^{\text {th }}$ revised. Edition. National Academic Press. Washington, DC

Oldfield J.E., 2002. Selenium World Atlas (2002 updated edition). Selenium-Tellurium Development Association (Editor). Grimbergen (Belgium)

Radostits O.M., Gay C.C., Hinchcliff K.W., Constable P.D., 2007. Veterinary Medicine: a Textbook of the Diseases of Cattle, Sheep, Pigs, Goats and Horses $10^{\text {th }}$ Edition. Saunders Ltd., Philadelphia (USA), pp. 923-946

Rayman M.P., 2004. The use of high-selenium yeast to raise selenium status: How does it measure up? Brit. J. Nutr. 92, 557-573

Rayman M.P., 2012. Selenium and human health. Lancet 379, 1256-1268

Richards C.J., Blalock H.M., Jacques K.A., Loveday H.D., 2011. Efficacy of feeding selenium enriched yeast to finishing beef cattle. Prof. Anim. Sci. 27, 1-8

Rowe L.J., Maddock K.R., Lonergan S.M., Huff-Lonergan E., 2004a. Influence of early postmortem protein oxidation on beef quality. J. Anim. Sci. 82, 785-793

Rowe L.J., Maddock K.R., Lonergan S.M., Huff-Lonergan E., 2004b. Oxidative environments decrease tenderization of beef steaks through inactivation of calpain. J. Anim. Sci. 82, 3254-3266

SAS, 2011. SAS/STAT 9.3 User's Guide. Version 9.3. SAS Institute Inc. Cary, NC

Shi L., Xun W., Yue W., Zhang C., Ren Y., Shi L., Wang Q., Yang R., Lei F., 2011. Effect of sodium selenite, Se-yeast and nanoelemental selenium on growth performance, Se concentration and antioxidant status in growing male goats. Small Ruminant Res. 96, 49-52

Spears J.W., 2000. Micronutrients and immune function in cattle. Proc. Nutr. Soc. 59, 587-594

Taylor J.B., Marchello M.J., Finley J.W., Neville T.L., Combs G.F., Caton J.S., 2008. Nutritive value and display-life attributes of selenium-enriched beef-muscle foods. J. Food Comp. Anal. 21, 183-186

Thomson C.D., 2004. Assessment of requirements for selenium and adequacy of selenium status: A review. Eur. J. Clin. Nutr. 58 391-402

Vignola G., Lambertini L., Mazzone G., Giammarco M., Tassinari M., Martelli G., Bertin G., 2009. Effects of selenium source and level of supplementation on the performance and meat quality of lambs. Meat Sci. 81, 678-685

Wang Y.X., Zhan X.A., Yuan D., Zhang X.W., Wu R.J., 2011a. Effects of selenomethionine and sodium selenite supplementation on meat quality, selenium distribution and antioxidant status in broilers. Czech J. Anim. Sci. 56, 305-313

Wang Y.X., Zhan X.A., Zhang X.W., Wu R.J., Yuan D., 2011b. Comparison of different forms of dietary selenium supplementation on growth performance, meat quality, selenium deposition, and antioxidant property in broilers. Biol. Trace Elem. Res. 143, 261-273

Weiss W.P., 2005. Selenium sources for dairy cattle. Proceedings of Tri-State Dairy Nutrition Conference. Fort Wayne, Indiana (USA)

Zhan X.A., Wang M., Zhao R.Q., Li W.F., Xu Z.R., 2007. Effects of different selenium source on selenium distribution, loin quality and antioxidant status in finishing pigs. Anim. Feed Sci. Tech. 132, 202-211 